\title{
Post-Implementation Benefits and Challenges of the Balanced Scorecard: Evidence from the Finance and Accounting Outsourcing Sector
}

\author{
Dileepa N. Samudrage ${ }^{1^{*}} \quad$ Darshika T. Jayewardene $^{1}$ \\ 1.Department of Accounting, University of Sri Jayewardenepura, Nugegoda, Sri Lanka \\ 2.Faculty of Graduate Studies, University of Sri Jayewardenepura, Nugegoda, Sri Lanka
}

\begin{abstract}
The aim of this paper is to evaluate post implementation benefits and challenges of the Balanced Scorecard (BSC) in the Finance and Accounting Outsourcing (FAO) sector in Sri Lanka. The generic idea of the BSC presented by Norton and Kaplan in the year 1992, may not be universally appropriate to all companies, and as a result there may be challenges faced throughout and after the implementation process of this tool. Hence, this study will focus on specifically examining the benefits and challenges faced by FAO companies in the post-implementation stage and discharge strategies to overcome the identified challenges. The FAO sector is selected since there is a noticeable number of entities that seem to be facing difficulties in the post implementation stage of BSC resulting in either discontinuation of it or using haphazard practices.-This study followed a quantitative approach and data were collected through questionnaires and document reviews. The study found that all respondents unanimously agreed on certain benefits, prevalent challenges and strategies to overcome identified challenges, for the success of the BSC. It was noted that while the BSC proves to deliver many benefits through its use, it may only be gained through careful implementation of the same. Also, it is important to consider many challenges prior to, during and after the course of the implementation and ensure that these are overcome through carefully devised strategies.
\end{abstract}

Keywords: Balanced Scorecard, Benefits, Challenges, Strategies, Finance and Accounting Outsourcing, Sri Lanka

DOI: $10.7176 /$ RJFA/10-22-10

Publication date: November $30^{\text {th }} 2019$

\section{Introduction}

Due to the increasing level of globalization and innovation, the corporate world has entered into a dynamic and very complex environment, in which they have to constantly improve themselves in their business models. As a result, many theories have emerged over time that allows companies to continually better themselves and focus on improving their performance. Historically companies were satisfied with just measuring the financial aspect of their performance, as it was sufficient for the regulatory and financial requirements of reporting. Moreover, these measures are designed to report on the stewardship of the money entrusted to management rather than on the strategic direction of the business (Letza, 1996). However, with the increasing competition in the market the traditional financial measures have proved to be inadequate thus giving rise to the increased attention to the nonfinancial metrics.

The implementation of a BSC can bring many merits to the organization as a whole. Moving away from a singular focus on financial performance, the company moves towards focusing on the outcome of the nonfinancial aspects of the business as well. The strategy and vision of the organization is translated into specific objectives under each quadrant of the scorecard, which is communicated throughout the organization. There by the whole organization, speaks the same language, in order to achieve the overall company goals.

Along with successful implementations, there could be unsuccessful implementations of the BSC that may arise in companies. This could be due to the inherent challenges and obstacles that a company may face due to various factors. Ho \& McKay (2002), compare two organizations, one that successfully implemented the framework, and another that abandoned the use of the same due to its ineffectiveness.

The concept of the Balanced Scorecard has been a topic of discussion for a period of time among developed economies. This concept is yet to take its full toll in Sri Lanka. However, many multinational companies within Sri Lanka have adopted this framework in view of a holistic approach to measuring performance.

According to literature the balanced scorecard prevails to be a dominant tool for performance measurement in large organizations. It is one of the most preferred and least criticized tools (Paranjape et al., 2006). However, in order to reap the potential benefits of this performance measurement system, an organization requires to overcome the widely prevailing problems affecting successful implementation. The balanced scorecard cannot be generically applied according to the available theory but requires much work and adaptation to the relevant

${ }^{1}$ Darshika T. Jayewardene was a postgraduate student at the time of pursuing this research. 
industry and company.

This study is a survey-based research within three selected companies in the Finance and Accounting outsourcing (FAO) sector of Sri Lanka that have already implemented the BSC method for performance measurement.

Thus, this paper focuses on identifying the potential benefits that may be gained by a company after the implementation of BSC, the challenges prevalent in the adoption of the framework and strategies that can be used to overcome the challenges identified.

\section{Prior Literature}

BSC was introduced by David Norton \& Robert Kaplan in 1992. Since its inception BSC has gained popularity as a framework for a holistic approach to measuring performance. As a strategic performance measurement tool BSC translates an organization's mission and strategy into a set of performance measures that provides the framework for implementing its strategy. It is called the BSC because it balances the use of financial and nonfinancial performance measures to evaluate short run and long run performance in a single report. Also, it attempts to integrate all the interests of key stakeholders, owners, customers, employees on a scorecard. A critical assumption of BSC is that each performance measure is part of a balanced cause-and-effect relationship in which leading measures (e.g., nonfinancial, drivers of future financial performance) drive lagging measures (e.g., financial, results of past actions) (Kaplan \& Norton 1996, Bean \& Jarnagin, 2002)

There are many ways in which a company may design, implement and work with the BSC. Ericsson Data $\mathrm{AB}$ in Sweden is considered as one of the pioneers of implementing BSC method. A study confirms the implementation of the BSC was a tedious process which required great time and energy, like the other organizations that adopted the framework. The study produces lessons and learnings through which other organizations planning to adopt the BSC may understand and learn to overcome the challenges they may have to face. (Olsson, et al., 2000).

Assiri et al. (2006) noted that BSC approach has gained wide acceptance mainly due to its intrinsic value to businesses and the aggressive marketing of the concept. For more than two decades varied organisations around the world, manufacturing and service, private and public, for profit and not-for-profit organizations have used BSC to achieve performance effective strategy execution (Kaplan \& Norton, 2005).

In a study of the implementation of the BSC in the hotel sector (McDonnell, 1995) it has been highlighted that performance measures used in the hotel sector revolve mainly around non-financial and non-quantitative factors, as this is a main influencing factor for its success. Empirical evidence suggests that information systems used in hotels lag behind the actual needs of the organization, especially it does not focus on the human resource aspect which is important for a hotel and also the performance measures used by the hotel should reflect the market position, management style, financial and competitive strategies of the organization. Thus, in order to support proper planning, decision making and control, a performance measurement tool such as the BSC becomes usable.

A study carried out by Geller (1985) identifies that in order to establish a fully-fledged performance measurement tool in a hotel, it is important for them to identify their goals and the critical success factors which will lead them to their goals, in order to develop the appropriate measures. Further, the need to continually update the measures to keep them relevant and useful is highlighted.

Reiterating other research findings Letza (1996) conducts a case study analysis of three vastly different companies from three different industries. The purpose of this study is to determine the design and implementation of the BSC in order to deliver strategy. Through this research the author confirms the premise that the generic BSC requires to be changed according to the specific requirement and culture of the company and the measures involved need to be driven by strategy. One of the benefits highlighted in this case study is the ability of the BSC to prevent sub-optimization through the requirement of considering important measures at the same time. Furthermore, it also has the ability to bring strategy and the vision of the organization to the forefront, and thereby motivate and commit employees to perform to the best of their ability in terms of improving the organization, by linking their performance to their incentives. The study also observes certain mistakes and it advices other companies to avoid them when implementing the BSC. Firstly, it is unnecessary to spend longer period of time in order to identify appropriate measures. Secondly, it is imperative to ensure that no area is left out of measurement. Every single aspect of the organization should be measured through the BSC. Finally, the implementation of the BSC could lead to conflicts between internal managers, resulting from removing the functional lines of authority, which requires to be managed.

Based on real world experience presented in Roest (1997) gained by Nolan, Norton \& Company and KPMG the following have been identified about the BSC method. According to this article it is said that all businesses are different to each other, therefore there will be no one standard solution. The variation will happen according to the internal and external environment of the organization and in turn the final design will have a bearing on the market position and the culture of the organization. One essential fact presented in many other surveys is the 
top management support which is always important. This becomes essential in the case of a change in a measurement. It must be noted that the beginning point of the BSC is always the strategy. Unless a company has a proper strategy in place it is difficult to implement a BSC framework. Once this is established, it may be converted to a realistic action plan through the BSC. It is necessary to identify the important aspects for the organization within the company as well as in the external environment. Without a clear vision on this there can be conflicts once the BSC is implemented.

As identified by many researchers Sanger (1998) agrees that, the measurement of financial measures alone provide less benefit to the company. Financial measures quantify the past. Therefore, the requirement of measurement of the future performance will be met by the introduction of the BSC, which provides all-round performance quantification. One of the important factors that ensures the success of the BSC is based on how appropriate, and the level of quality of the measures chosen, which indicates the level of progress towards the goals of the organization. The BSC implementation is a very tedious process. This appears to be one of the reasons as to why companies are reluctant to adopt this tool for performance measurement.

Evans (2005) asserts that a hotel combines many activities and differing cost structures. As a result, varied performance measurements are required which are facilitated by the BSC. The BSC has the ability to strengthen the culture of an organization, inspire employees to pay attention to both long- and short-term performance, reward and recognize as well as communicate best practice and strategy throughout the organization.

Accordingly, it is observed that a large number of hotels, measure their financials in terms of operating revenue, customer satisfaction in terms of ratings and complaints, internal business processes in terms of response time for complaints and errors. The innovation and learning perspective is measured far less when compared to the other three perspectives. However even though the concept of BSC is widely promoted and accepted, majority of the hotels do not use the BSC tool outright. Rather they use other performance measurement tools similar to the four perspectives included in the BSC.

The study reveals that there are many benefits that are generated from adopting the BSC method in the hotel sector. Some of them being, that managers are forced to focus on both the long and short term indicators and they are well aware of the consequences of their decisions taken, rewards team work and linked to incentives, sharing of best practices employed in the industry as well as performance and strategy related information and allowing managers to identify negatives before it impacts the financial performance. However, the article also presents certain difficulties and challenges of adopting the BSC. Namely, the long and complex process of implementation, high degree of time and effort involved, requirement to align the strategy with the measures in the BSC, continuous need to monitor and revise the BSC, so it stays relevant and non-availability of an 'off the shelf' tool are some of the limitations, failure to establish cause and effect links between perspectives, failure to obtain the support of the employees as well as the higher level managers and mistakenly taking data as information that can be used are some of the added difficulties that the BSC poses.

A study conducted by Paranjape et al. (2006) notes that, the implementation of the BSC is 'Operationally' difficult. Further, it states that there is no evidence to suggest that implementation of the same leads to improvement in performance. One of the main areas of concern is how to measure, involving questions such as how the measures are selected and how the selected measures are put into practice as well as how to keep them up to date and relevant to the ever-changing nature of an organization. One should not blindly accept the BSC as it could lead to improper measures and behavior. Further, introducing new measures, to existing performance measurement system lead to costly and inaccurate results.

According to Johanson, et al. (2006) various stories of BSC implementations have been analysed in different studies and according to them there are successes and failures but more of success stories. For BSC to succeed an important factor that comes into play is top managers' commitment as well as middle managers' and employee participation. In addition, a culture of performance excellence, proper training and education, clear understanding of the vision and strategy of the organization is important. Finally, it should be linked with incentives and appropriate resources to implement the BSC should be available.

Assiri et al. (2006) takes into consideration different organizations in different sectors in order to describe the BSC implementation. As such it provides principles and techniques that are required for a successful implementation and to generate maximum benefit from the same. The study uses three data sources namely, survey questionnaire, case study analysis, and secondary case studies. Accordingly, a number of critical success factors that are essential in order to carry out a successful implementation have been named. The same has been divided in to three separate levels, namely dominant, main and supporting factors. In detail, the dominant factors relate to the factors that are detrimental to the implementation of the BSC, if absent may result in failure of the implementation. They are the senior management commitment throughout the implementation, which is highlighted in many previous research papers, an implementation team and also identifying the appropriate perspectives. The main factors are those which are critical at a medium level. While there are many factors, the most important ones can be identified as appropriate identification of the company's vision, mission, strategies and values, training needs in terms of facilitating the change towards the implementation, setting objectives, 
measures and KPI's, rolling out an implementation plan and linking the measurement to rewards and incentives. Finally, the supporting factors are those that are less critical but are required for a successful implementation. The BSC must be integrated to the management system of the organization, coupled with self-assessment models, measures finalized and refined periodically in order to be relevant. Thus, is can be viewed that these are very important findings which could be adopted by organizations intending to implement or improve their existing BSC.

Through an exploratory study conducted on two case studies, as well as through analysis of web servicerelated documents, standard operating procedures and internal polices Ratnasingam (2009), focuses on examining the quality of web services through BSC method. According to this research over $50 \%$ of the Fortune 500 companies, have implemented the BSC, and indicates that the BSC serves as a monitoring mechanism for performance, communication tool as well as a management system, that focuses on the vision of the business. According to the findings, in terms of the learning and growth perspective it has been revealed that in both companies, best practices in the industry are very important to them, thus both companies continually strive to provide training and skills for their employees, to increase the use of web service. Also, it proves that the quality of the technology can improve the internal business operations through automating the process, eliminating nonvalue adding activities to improve process design.

A study conducted by Soderberg et al. (2011) demonstrate that there are differences in the implementation and use of BSC in different firms. Accordingly, it explains that the BSC contains two sets of attributes, one relating to the structure and the other relating to the use. The three structural features indicate that the measures are required to be derived from strategy, the type and number of measures used in the BSC should be balanced and also that the measures are linked causally. In other words, that there is a leading and lagging indicator relationship, ultimately improving the financial aspect creating shareholder and stakeholder value. In terms of the use attributes, this contains two features, namely double loop learning, process of updating the BSC measure if the actual results differ from the expected results, and Tie-in to compensation. Based on the above a webbased survey is conducted on a sample of companies in which the same is tested in terms of the level of usage of the BSC and how each one differs from another company in a different stage. Accordingly, the results indicate that one vital factor for the successful implementation of the BSC, is the commitment from the top-level management and also requirement to be definitely tied to the organizational strategy in order to be effective. Unless the measures are balanced and have a causal relationship amongst each other it is likely to fail. The companies examined have established the performance measurement tool at different levels and it is also observed that there is a marked difference between the companies in terms of the senior management support, incorrect measures, and the measures not being causally linked.

Considering the implementation of the BSC in public sector organizations, Northcott \& Taulapapa (2012) claims that there is general awareness of the BSC method in the public sector of New Zealand and it is used as a performance management tool and it provides various benefits. It also highlights 2 factors for the successful implementation of the BSC method which are the requirement to modify the scorecard according to the need of the organization and continuous learning prior to implementing as well as while using it. The study also revealed certain barriers to the implementation of a successful balanced scorecard, in particular using a substitute performance measurement tool, the size of the organization, the unavailability of the resources to generate information required to support the BSC method, the lack of time and commitment towards the implementation process and finally the lack of top management support in the design and implementation of the tool.

Dimitropoulos, et al. (2017) confirms the above and states that a public-sector organization operates under tight budget constraints, as well as scarce economic resources. There are many stakeholders for such an organization and thus required to ensure all varying stakeholder needs are met while the required level of service quality is also maintained. It is required to measure results in order to confer whether the money provided to them is being invested appropriately. By undertaking this study, it is observed on how the BSC is implemented in a non-profit organization in the view of understanding goal setting, setting performance indicators and evaluation of the outcome based on the BSC. Further it also tries to bridge the gap in literature in the scarcity of research on the benefits of implementation of the BSC in the non-profit sector. According to the results it was observed that, with the implementation of the BSC the organization was able to manage their expenses with the constraints given to them, along with an increase in the revenue. Furthermore, it gave rise to improved internal processes. This came about through the staff participation in various training seminars. In addition, and an increased level of customer satisfaction was also achieved. The citizen is the most important stakeholder for this non- profit organization, and this became an important revelation of the said organization. Accordingly, the study confirms previous studies conducted by various researchers. In addition to the above, through the research it was also identified that human resource is an important element of successfully applying the BSC. A main factor for failure is the lack of dedication and commitment from the senior managers of an organization. In addition, proper preparation and training should also be provided to the staff for proper implementation and usage of the performance management system. 
Finally, in a study conducted more closer to home, Wickramasinghe, et al. (2008) taking on a natural, subjective ontology and a post-positivistic epistemologist approach, explains that the BSC has had a gradual rise and fall within the country of Sri Lanka. This can be seen from the example of Alpha Company in which the Managing Director who received his education aboard learnt about the BSC concept and on his return to the island and his father's company, he wanted to establish the same within his organization. The reason for this was his need to systematize and align the family business. CIMA SL took the initiative to propagate the concept of BSC within Sri Lanka. By organizing many workshops and awareness programs and even bringing Robert Kaplan himself to Sri Lanka, CIMA SL managed to create interest in this too, among Sri Lankan Companies. However, it must be noted that the BSC concept has become an accountant led approach and lacks interest from other professions. As a result, Alpha hired a consultant to take on a project on BSC initiation within the company. However, the approach taken by the consultant from the beginning itself had its limitations. The implementation was not driven by the needs of the company nor did it address neither the business nor its environment. Further it took a command method rather than a participative method. Additionally, it did not consult the lower level employees and also tried to control employees. All this led to the fall of the BSC within the entity. Results of the inappropriate design led to non-accounting professionals disapproving the tool and criticizing the additional burden on them. Gradually this resulted in the overall enthusiasm and commitment for the project to diminish, finally resulting in their focus only on the financial measures. The project failed to be an effective management control system and also brought out the difficulties in bridging the different professional statuses.

\section{Case Study Companies}

The selected industry for the proposed research topic is the Finance and Accounting Outsourcing (FAO) sector of Sri Lanka. Three leading companies within FAO sector were selected as case companies. The management of those companies wished their companies to remain anonymous therefore the three companies are code-named as WINS, EDP and ACCL.

\section{WINS}

WINS is listed in the NYSE. It is a global provider of Business Process Management. The company has over 200 clients worldwide, to which they provide expertise in the areas of customer care, finance and accounting, human resource solutions, research and analytics, technology solutions, and industry-specific back-office and frontoffice processes. WINS employs a workforce of about 34,000 employees, out of which a staff of 840 are employed in one of its delivery centres located in Sri Lanka. The Company earned a net revenue of USD 602.5 Million in the year ending March 31st, 2017 and of the same 2.5\% was generated in Sri Lanka.

\section{EDP}

EDP was established in the year 2014. A fully owned subsidiary of HSBC Holdings, this global service centre offers high quality financial and professional services to the worldwide operations and businesses of HSBC Holdings. The company specializes in the areas of general banking services, Financial Crime Compliance, Global HUB \& Core Banking Support, Global Publishing Services, Global Trade \& Receivables Finance, HSBC Securities Services and Know Your Customer Operations. As at 30th June 2017, EDP had a staff of 1244 employees. EDP earned a total operating income of Rs. 11 billion in the second quarter ended 30th June 2017. Of the same profit for the same period was recorded as 3.6 billion. (HSBC, 2017)

\section{ACCL}

ACCL is a global management and professional services company. The company is proficient in the areas of strategy, consulting, digital, technology and operations services. ACCL is a Fortune 500 company established in Dublin, Ireland in the year 1989. Around the world, the company is serving clients in over 120 countries and it has employed 384,000 staff. For the 3rd quarter of the year 2017, the company was able to amass a revenue of 9.4 billion dollars, while the gross profit amounted to a 2.9 billion dollars, which was reported as a $31 \%$ GP margin (accenture, 2017). In the year 2013, Brandix, largest exporter of Sri Lanka, signed an agreement with ACCL Sri Lanka to provide Business process outsourcing in the areas of Human resources, Finance and Accounting and procurement. Since then the company with the collaboration has been doing significantly well gaining clients on board to provide automated business processes providing everything 'as a service'.

\section{Methodology}

The framework adopted in this study proposes to undertake an exploratory investigation on the benefits and challenges of the implementation of the BSC method. Further it also goes on to define the strategies in order to overcome the challenges identified. As such the research design intends to take on a quantitative nature of data collection and investigation. This includes;

- Comprehensive study and analysis of relevant literature and case studies of balanced scorecard implementation studied by previous authors

- Survey conducted through a semi-structured questionnaire distributed among managers in 3 companies in the Finance and Accounting outsourcing sector of Sri Lanka. 


\subsection{Data Collection}

The data was gathered by distributing an online questionnaire prepared after comprehensive analysis of existing literature. The completed draft questionnaire was sent for expert opinion. Based on the expert opinion and feedback received the researchers amended the same and finalized the questionnaire. The questionnaire survey queried on the three different aspects relevant to the study conducted. Namely on benefits experienced through the implementation of the performance management tool, the challenges faced during and after the implementation of the balanced scorecard and finally in the perspectives of the respondents' points on which the company could have improved in order to overcome the challenges faced. A five-point Likert Scale questionnaire was used for the purpose of data collection.

The responses obtained were compared against information gathered through the extensive study of past literature in order to establish the topic under review, ensuring that the information obtained was comprehensive.

\section{Data Analysis and Findings}

The completed online questionnaire was distributed amongst a selected sample of 100 employees amongst all 3 companies selected as case studies for the research project. The selected sample included respondents from the operational, supervisory, middle management and top management cadres. Accordingly, out of the sample to which the questionnaire was sent, 80 respondents completed and submitted the questionnaire, thus resulting in a response rate of $80 \%$. Based on the responses received from 80 respondents, the following analyses were done to understand the basic demographic features of those respondents.

\subsection{Profile of the Respondents}

Of the 80 respondents participated in this study, $42.5 \%$ were males while $57.5 \%$ were females. Similarly, of the 80 respondents, $25 \%$ belonged to the operational level, $32 \%$ to the supervisory level, $29 \%$ to the middle management level and $14 \%$ to the top management level. This reveals that majority of the respondents belonged to the supervisory category.

Another analysis was performed to understand the respondents' experience levels in terms of the current organization as well as in the Finance and Accounting Outsourcing sector (FAO) as a whole. Accordingly, in terms of the experience in the current organization, $10 \%$ had less than 1 year of experience, $53.7 \%$ had $1-5$ years' experience, $33.7 \%$ had 6-10 years' experience, and a mere $0.02 \%$ had $11-15$ years' experience. In terms of the experience years in the FAO sector of Sri Lanka as a whole, $2 \%$ had less than 1-year experience, 45\% had 15 years' experience, $44 \%$ had 6-10 years' experience, and 9\% had 11-15 years' experience in the industry. Accordingly, we may identify that majority of the respondents have a considerable experience level in the FAO sector.

\subsection{Evaluation of Perceived Benefits}

In order to analyse perceived benefits, analysis of mean values, one sample T-test and one-way Anova test were performed. The results of those three tests are presented in Table 1.

5.2.1 Mean analysis of perceived benefits

Analysis of mean values was performed to identify the most important perceived benefits. Ranking of mean values of perceived benefits from BSC reveal that the mean values are between 3.65 and 4.19 (see Table 1). It indicates that all benefits have a mean value which is above the average mean value of 3 . Therefore, it is apparent that managers agree on an above average rate that these benefits lead to performance improvements. Benefit B1 is ranked highest with a mean value of 4.19. This result indicates that managers of these organizations are more concerned towards other perspectives of BSC (such as Customer perspective, learning \& growth perspective, and internal business processes perspective) rather than on financial perspective. Improvements/progressions of these perspectives are finally reflected from the long-term financial performance. This finding of the study is consistent with the findings of Northcott \& Taulapapa (2012).

5.2.2 One Sample T-test results of perceived benefits

One sample t-test was conducted to analyse whether the sample mean in each variable tested, also known as the 'test variables', of the Balanced Scorecard (BSC) is statistically different from a known or hypothesized population mean (which is 3 in this analysis). Table 1 presents the results of one sample t-test conducted for perceived benefits. We can observe that the ' $t$ ' statistic of all eleven variables indicates a positive value ranging from 8.396 to 18.584 . 
Table 1: Summary of Statistical tests conducted for Perceived Benefits

\begin{tabular}{|c|c|c|c|c|c|c|c|c|c|}
\hline \multirow{3}{*}{ Ref. } & \multirow{3}{*}{ Indicators } & \multirow{3}{*}{ Mean } & & & \multicolumn{5}{|c|}{ One-way Anova } \\
\hline & & & \multicolumn{2}{|c|}{ T- test } & \multirow{2}{*}{$\begin{array}{c}\text { Gend. } \\
\text { Sig. }\end{array}$} & \multirow{2}{*}{$\begin{array}{c}\text { Job } \\
\text { level }\end{array}$} & \multirow{2}{*}{$\begin{array}{c}\text { Exp. } \\
\text { Sig. }\end{array}$} & \multirow{2}{*}{$\begin{array}{c}\text { Clients' } \\
\text { Nature } \\
\text { Sig. }\end{array}$} & \multirow{2}{*}{$\begin{array}{c}\text { C'xity }^{\prime} \\
\text { Sig. }\end{array}$} \\
\hline & & & $\mathbf{t}$ & Sig. & & & & & \\
\hline B1 & $\begin{array}{l}\text { Targets were set that directed } \\
\text { our performance towards } \\
\text { achieving our organization's } \\
\text { objectives in areas beyond } \\
\text { simple financial outcomes }\end{array}$ & 4.190 & 14.740 & 0.000 & 0.177 & 0.000 & 0.683 & 0.345 & 0.330 \\
\hline B2 & $\begin{array}{l}\text { BSC ensures focus on the long- } \\
\text { term success and revenue of the } \\
\text { organization }\end{array}$ & 4.150 & 18.584 & 0.000 & 0.094 & 0.000 & 0.115 & 0.688 & 0.213 \\
\hline B3 & $\begin{array}{l}\text { BSC can translate and clarify } \\
\text { the organizational vision, } \\
\text { strategic plans and expected } \\
\text { performance throughout the } \\
\text { company efficiently and } \\
\text { effectively, and improve } \\
\text { awareness }\end{array}$ & 4.000 & 13.634 & 0.000 & 1.000 & 0.005 & 0.348 & 0.282 & 0.147 \\
\hline B4 & $\begin{array}{l}\text { BSC method promoted team } \\
\text { work culture and improved } \\
\text { cooperation and learning within } \\
\text { teams }\end{array}$ & 3.900 & 12.809 & 0.000 & 0.197 & 0.067 & 0.253 & 0.794 & 0.095 \\
\hline B5 & $\begin{array}{l}\text { BSC provides a genuine } \\
\text { understanding of the different } \\
\text { dimensions of strategic decision } \\
\text { making }\end{array}$ & 3.900 & 11.270 & 0.000 & 0.597 & 0.404 & 0.693 & 0.214 & 0.585 \\
\hline B6 & $\begin{array}{l}\text { BSC acts as a motivational tool } \\
\text { for the organization }\end{array}$ & 3.900 & 11.270 & 0.000 & 0.075 & 0.002 & 0.183 & 0.675 & 0.604 \\
\hline B7 & $\begin{array}{l}\text { BSC provides focus and clear } \\
\text { lines of accountability }\end{array}$ & 3.870 & 11.475 & 0.000 & 0.935 & 0.010 & 0.897 & 0.130 & 0.931 \\
\hline B8 & $\begin{array}{l}\text { The BSC is linked to bonus } \\
\text { payments, thus facilitated an } \\
\text { understanding of performance } \\
\text { expectations }\end{array}$ & 3.840 & 8.396 & 0.000 & 0.702 & 0.968 & 0.666 & 0.373 & 0.203 \\
\hline B9 & $\begin{array}{l}\text { BSC method has enabled the } \\
\text { entity to achieve goal } \\
\text { congruence across the entity }\end{array}$ & 3.800 & 8.923 & 0.000 & 0.737 & 0.057 & 0.752 & 0.112 & 0.261 \\
\hline B10 & $\begin{array}{l}\text { The BSC enables to track our } \\
\text { performance over all critical } \\
\text { activities over time }\end{array}$ & 3.710 & 9.342 & 0.000 & 0.882 & 0.095 & 0.628 & 0.076 & 0.483 \\
\hline B11 & $\begin{array}{l}\text { BSC gives management a } \\
\text { concise set of information to } \\
\text { gauge performance and direct } \\
\text { improvements }\end{array}$ & 3.650 & 9.403 & 0.000 & 0.690 & 0.658 & 0.081 & 0.865 & 0.421 \\
\hline
\end{tabular}

Note: Gend - Gender; Exp. - Experience; C'xity - Complexity

(Source: Survey data)

Under the null hypothesis we would expect the ' $\mathrm{t}$ ' statistic to be zero, where the mean is equal to 3 . According to this result it can be seen that ' $t$ ' values lie more to the right tail of the distribution. In order to determine whether to reject the null hypothesis for each variable, it must be checked whether it lies far enough in the distribution. This could be determined from the ' $p$ ' value or significance value for all variables. Since all ' $p$ ' values are significant at $99 \%(\mathrm{p}<0.001)$ confidence level, we can conclude that the population means are statistically and significantly different. Hence, we may reject the null hypothesizes, in favour of the alternative hypothesizes. This suggests that the BSC implementation provides all of the identified benefits (see Table 1) for the FAO organizations.

This result is consistent with the two studies conducted by Evans (2005) and Letza (1996). In both studies, authors point out that the benefits have the ability to outweigh the challenges that one might face in 
implementing the tool. It is conclusive that "Organizations perceived it as a useful performance measurement and management tool" (Northcott \& Taulapapa, 2012).

5.2.3 One Way Anova test results of perceived benefits

The one-way analysis of variance (ANOVA) is used to determine whether there are any statistically significant differences between the means of different variables used in this study. Consequently, the ANOVA test was performed to see whether the mean values of perceived benefits are significantly different in terms of different genders, job levels, experiences, nature of clients, and complexity of operations.

5.2.3.1 One-way Anova test between perceived benefits and gender

The first one-way ANOVA test was conducted between perceived benefits and gender. It was examined to see whether the mean values of perceived benefits are significantly different between males and females. The results of the analysis are shown in Table 1. It is apparent that all the resultant 'p' values are above 0.075 . It indicates that none of the differences is significant at the $95 \%$ confidence level. Therefore, we can conclude that there is no statistically significant difference between the responses provided by the male and female respondents in relation to the perceived benefits.

5.2.3.2 One-way Anova test between perceived benefits and job level

The next one-way ANOVA test was between perceived benefits and job levels of respondents. This test was aimed at examining whether the mean values of perceived benefits are significantly different between different job levels. The results of the analysis are presented in Table 1. According to the results, it is apparent that benefits B4, B5, B8, B9, B10 and B11 have 'p' values which are above 0.05 indicating that they are not significant at $95 \%$ confidence level. Therefore, we can conclude that for those six perceived benefits, there is no statistically significant difference between the responses provided by respondents working at different levels in the organization.

However, Table 1 further indicates that benefits B1, B2, B3, B6 and B7 have 'p' values less than 0.05, indicating that they are significant at $95 \%$ confidence level. Therefore, it is apparent for those benefits, there is a significant difference between the responses provided by respondents working in different job levels. This difference was further analysed using 'Post Hoc Test' of SPSS. From the analysis, it could be revealed that the majority of the difference lies between the operational level employees against the Top and middle management level employees. Therefore, it can be highlighted that the benefits perceived by the operational staff significantly vary from the benefits perceived by the top management and middle management staff of the company.

5.2.3.3 One-way Anova test between perceived benefits and total experience

One-way ANOVA test between perceived benefits and total experience was conducted to examine whether the mean values of perceived benefits are significantly different between employees with different levels of experience. The results are depicted in Table 1. From the results it is evident that none of the benefits are significant at $95 \%$ confidence level $(\mathrm{p}>0.05)$. Therefore, we can conclude that there is no statistically significant difference of the perceived benefits between employees with different experience levels.

5.2.3.4 One-way Anova test between perceived benefits and nature of client base

The next one-way ANOVA test was between perceived benefits and nature of client base. This test was done to determine whether the mean values of perceived benefits are significantly different between different client bases. The results of the analysis are shown in Table 1. Results reveal that for all perceived benefits ' $p$ ' values are above 0.05 , indicating that they are not significant at $95 \%$ confidence level. Therefore, we can conclude that there is no statistically significant difference of perceived benefits between different client bases.

5.2.3.5 One-way Anova test between perceived benefits and complexity of operations

The final one-way ANOVA test was between perceived benefits and complexity of operations of the organizations. This was performed to find out whether the mean values of perceived benefits are significantly different between operations with different complexity levels. The results are given in Table 1 . The results show that none of the benefits are significant at $95 \%$ confidence level $(p>0.05)$. Therefore, we can conclude that there is no statistically significant difference of the perceived benefits between operations with different complexity levels.

\subsection{Evaluation of Perceived Challenges}

In order to analyse perceived challenges from different perspectives, analysis of mean values, one sample T-test and one-way Anova test were performed. The results of those three tests are presented in Table 2.

5.3.1 Mean analysis of perceived challenges

Mean value analysis was conducted to identify the most crucial perceived challenges. Ranking of mean values of perceived challenges of BSC implementation reveals that the mean values range between 3.21 and 4.00 (see Table 2). It is apparent that all challenges have a mean value which is above the average mean value of 3 . Accordingly, it may be concluded that all managers agree on an above average rate that all identified challenges are obstacles to the successful implementation of the BSC performance measurement tool. 
Table 2: Summary of statistical tests conducted for perceived challenges

\begin{tabular}{|c|c|c|c|c|c|c|c|c|c|}
\hline \multirow{3}{*}{ Ref. } & \multirow{3}{*}{ Indicators } & \multirow{3}{*}{ Mean } & \multirow{2}{*}{\multicolumn{2}{|c|}{ T-test }} & \multicolumn{5}{|c|}{ One-way Anova } \\
\hline & & & & & \multirow{2}{*}{$\begin{array}{c}\text { Gend. } \\
\text { Sig. }\end{array}$} & \multirow{2}{*}{$\begin{array}{c}\text { Job } \\
\text { level }\end{array}$} & \multirow{2}{*}{$\begin{array}{c}\text { Exp. } \\
\text { Sig. }\end{array}$} & \multirow{2}{*}{$\begin{array}{l}\text { Clients' } \\
\text { Nature } \\
\text { Sig. }\end{array}$} & \multirow{2}{*}{$\frac{C^{\prime} x i t y}{\text { Sig. }}$} \\
\hline & & & $\mathbf{t}$ & Sig. & & & & & \\
\hline $\mathrm{C} 1$ & $\begin{array}{l}\text { Lack of proper training and } \\
\text { education prior to and during } \\
\text { the implementation process of } \\
\text { the tool }\end{array}$ & 4.000 & 13.634 & 0.000 & 0.169 & 0.397 & 0.178 & 0.071 & 0.028 \\
\hline $\mathrm{C} 2$ & $\begin{array}{l}\text { Lack of time for the design } \\
\text { and implementation process }\end{array}$ & 3.840 & 9.522 & 0.000 & 0.200 & 0.001 & 0.011 & 0.106 & 0.080 \\
\hline $\mathrm{C} 3$ & $\begin{array}{l}\text { Treating the Balanced } \\
\text { Scorecard as a one-time } \\
\text { measurement project }\end{array}$ & 3.750 & 6.625 & 0.000 & 0.580 & 0.000 & 0.006 & 0.070 & 0.197 \\
\hline $\mathrm{C} 4$ & $\begin{array}{l}\text { Lacks clarity of vision \& } \\
\text { strategy }\end{array}$ & 3.750 & 6.795 & 0.000 & 0.570 & 0.000 & 0.290 & 0.106 & 0.401 \\
\hline $\mathrm{C} 5$ & $\begin{array}{l}\text { Lack of appropriate resources } \\
\text { for the design and } \\
\text { implementation of the BSC }\end{array}$ & 3.710 & 7.846 & 0.000 & 0.758 & 0.001 & 0.346 & 0.083 & 0.156 \\
\hline C6 & $\begin{array}{l}\text { Lack of top management } \\
\text { commitment }\end{array}$ & 3.490 & 3.998 & 0.000 & 0.015 & 0.000 & 0.212 & 0.409 & 0.425 \\
\hline $\mathrm{C} 7$ & $\begin{array}{l}\text { Lack of participation from the } \\
\text { middle managers' and } \\
\text { employees }\end{array}$ & 3.410 & 3.469 & 0.001 & 0.829 & 0.000 & 0.089 & 0.283 & 0.407 \\
\hline $\mathrm{C} 8$ & $\begin{array}{l}\text { The size of the organization } \\
\text { was a challenge for the } \\
\text { implementation of the tool }\end{array}$ & 3.380 & 3.502 & 0.001 & 0.137 & 0.111 & 0.951 & 0.017 & 0.047 \\
\hline C9 & $\begin{array}{l}\text { Failure to link measures to the } \\
\text { strategy of an organization }\end{array}$ & 3.320 & 3.013 & 0.003 & 0.248 & 0.033 & 0.446 & 0.433 & 0.179 \\
\hline $\mathrm{C} 10$ & $\begin{array}{l}\text { Failure in the design of the } \\
\text { BSC (ex. too few / too many } \\
\text { measures of performance) }\end{array}$ & 3.210 & 2.156 & 0.034 & 0.652 & 0.000 & 0.436 & 0.093 & 0.020 \\
\hline
\end{tabular}

Note: Gend - Gender; Exp. - Experience; C'xity - Complexity

(Source: Survey data)

Challenge $\mathrm{C} 1$ is ranked highest with a mean value of 4.00. This indicates that managers of these organizations have had lack of proper training and education prior to and during the BSC implementation process. In other words, they believe that training and education is an important element for a successful implementation of new tools like BSC. This perception is consistent with the findings of Assiri et al. (2006) too where they stated that 'employees' training and education initiatives may help facilitate this change by providing employees with the knowledge and skills they require to adapt to and to lead this change process'.

5.3.2 One Sample T-Test results of perceived challenges

Table 2 illustrates the results of one sample t-test conducted for perceived challenges. According to Table 2, it is apparent that the ' $t$ ' statistic of all ten variables have positive values ranging from 2.156 to 13.634. Under the null hypothesis we would expect the ' $t$ ' statistic to be zero, where the mean is equal to 3 . According to this result it can be seen that ' $t$ ' values lie more to the right tail of the distribution. In order to determine whether to reject the null hypothesis for each variable, it must be checked whether it lies far enough in the distribution. This could be determined from the 'p' value or significance value for all variables. Since all ' $p$ ' values are significant at $95 \%(\mathrm{p}<0.05)$ confidence level, implying that the population means are statistically and significantly different. Consequently, we may reject the null hypothesizes, in favour of the alternative hypothesizes. This suggests that FAO organizations face all the challenges identified in Table 2 above during the process of BSC design and implementation. These results are consistent with the findings of Habte (2015), who states that "challenges were encountered during the implementation process that hindered effective use of the BSC to its intended objective".

5.3.3 One-Way Anova test results of perceived challenges

5.3.3.1 One-way Anova test between perceived challenges and gender

The first one-way ANOVA test was conducted between perceived challenges and gender. This was examined to see whether the mean values of perceived challenges are significantly different between males and females. The results of the analysis are shown in Table 2. It is apparent that all the resultant ' $p$ ' values are above 0.05 , except for the challenge C6. Therefore, except for C6, other challenges are not significant at the 95\% confidence level. 
Therefore, we can conclude that there is no statistically significant difference between the responses provided by the male and female respondents in relation to the perceived challenges, except for the challenge C6.

5.3.3.2 One-way Anova test between perceived challenges and job level

The next one-way ANOVA test was between perceived challenges and job levels of respondents. This test was aimed at examining whether the mean values of perceived challenges are significantly different between different job levels. The results of the analysis are presented in Table 2. According to the results, it is apparent that challenges $\mathrm{C} 1$, and $\mathrm{C} 8$, have ' $\mathrm{p}$ ' values which are above 0.05 indicating that they are not significant at $95 \%$ confidence level. Therefore, we can conclude that for those two perceived challenges, there is no statistically significant difference between the responses provided by respondents working at different levels in the organization.

However, Table 2 further indicates that other eight challenges have 'p' values less than 0.05 , indicating that they are significant at 95\% confidence level. Therefore, it is apparent for those challenges, there is a significant difference between the responses provided by respondents working in different job levels. This difference was further analysed using 'Post Hoc Test' of SPSS. From this analysis, it was revealed that for each challenge posed, each level has varying opinions and hence do not indicate any sort of relation.

5.3.3.3 One-way Anova test between perceived challenges and total experience

One-way ANOVA test between perceived challenges and total experience was conducted to examine whether the mean values of perceived challenges are significantly different between employees with different levels of experience. The results are depicted in Table 2. From the results it is evident that except for challenges $\mathrm{C} 2$ and $\mathrm{C} 3$, none of the other challenges are significant at 95\% confidence level ( $\mathrm{p}>0.05)$. Therefore, we can conclude that other than for $\mathrm{C} 2$ and $\mathrm{C} 3$, there is no statistically significant difference of the perceived challenges between employees with different experience levels.

5.3.3.4 One-way Anova test between perceived challenges and nature of client base

The next one-way ANOVA test was between perceived challenges and nature of client base. This test was done to determine whether the mean values of perceived challenges are significantly different between different client bases. The results of the analysis are shown in Table 2. Results reveal that for all perceived challenges, except for C8, have 'p' values that are above 0.05 indicating that they are not significant at $95 \%$ confidence level. Therefore, we can conclude that, except for the challenge $\mathrm{C} 8$, there is no statistically significant difference of perceived challenges between different client bases.

5.3.3.5 One-way Anova test between perceived challenges and complexity of operations

The final one-way ANOVA test was between perceived challenges and complexity of operations of the organizations. This was performed to find out whether the mean values of perceived challenges are significantly different between operations with different complexity levels. The results are given in Table 2 . The results show that three of the challenges $(\mathrm{C} 1, \mathrm{C} 8$, and $\mathrm{C} 10)$ are significant at $95 \%$ confidence level $(\mathrm{p}<0.05)$. However, other seven challenges found to be not significant at $95 \%$ confidence level.

\subsection{Evaluation of the perceived strategies to overcome the identified challenges}

In order to analyse perceived strategies from different perspectives, analysis of mean values, one sample $\mathrm{T}$-test and one-way Anova test were performed. The results of those three tests are presented in Table 3.

5.4.1 Mean analysis of perceived strategies

Analysis of mean values was performed to identify the most important perceived strategies to overcome the identified challenges and successfully implement BSC within the organizations. Results are shown in Table 3. 
Table 3: Summary of Statistical tests conducted for Perceived strategies to overcome the identified challenges

\begin{tabular}{|c|c|c|c|c|c|c|c|c|c|}
\hline \multirow{3}{*}{ Ref. } & \multirow{3}{*}{ Indicators } & \multirow{3}{*}{ Mean } & \multirow{2}{*}{\multicolumn{2}{|c|}{ T -test }} & \multicolumn{5}{|c|}{ One-way Anova } \\
\hline & & & & & \multirow{2}{*}{$\begin{array}{c}\text { Gend. } \\
\text { Sig. }\end{array}$} & \multirow{2}{*}{$\begin{array}{c}\begin{array}{c}\text { Job } \\
\text { level }\end{array} \\
\text { Sig. }\end{array}$} & \multirow{2}{*}{$\begin{array}{l}\text { Exp. } \\
\text { Sig. }\end{array}$} & \multirow{2}{*}{$\begin{array}{c}\text { Clients' } \\
\text { Nature } \\
\text { Sig. }\end{array}$} & \multirow{2}{*}{$\frac{C^{\prime} x i t y}{\text { Sig. }}$} \\
\hline & & & $t$ & Sig. & & & & & \\
\hline S1 & $\begin{array}{l}\text { Ensure appropriate resources to } \\
\text { implement the BSC is available }\end{array}$ & 4.330 & 20.068 & 0.000 & 0.245 & 0.073 & 0.229 & 0.929 & 0.027 \\
\hline $\mathrm{S} 2$ & $\begin{array}{l}\text { Provide appropriate training } \\
\text { and education and } \\
\text { communication for all } \\
\text { employees }\end{array}$ & 4.290 & 16.968 & 0.000 & 0.358 & 0.005 & 0.330 & 0.141 & 0.224 \\
\hline $\mathrm{S} 3$ & $\begin{array}{l}\text { Ensure the BSC is reviewed } \\
\text { and revised regularly in order } \\
\text { to keep it relevant to any } \\
\text { changes }\end{array}$ & 4.210 & 14.003 & 0.000 & 0.607 & 0.418 & 0.526 & 0.109 & 0.044 \\
\hline $\mathrm{S} 4$ & $\begin{array}{l}\text { Ensure commitment and } \\
\text { participation of both the top } \\
\text { management as well as the } \\
\text { users of the BSC, and avoid } \\
\text { any conflicts }\end{array}$ & 4.170 & 14.491 & 0.000 & 0.546 & 0.476 & 0.298 & 0.085 & 0.030 \\
\hline S5 & $\begin{array}{l}\text { Ensure a competent project } \\
\text { team / dedicated process is } \\
\text { established for the design and } \\
\text { implementation }\end{array}$ & 4.160 & 17.823 & 0.000 & 0.331 & 0.146 & 0.102 & 0.022 & 0.010 \\
\hline S6 & $\begin{array}{l}\text { Link the BSC and performance } \\
\text { with incentives }\end{array}$ & 4.140 & 14.770 & 0.000 & 0.826 & 0.002 & 0.135 & 0.262 & 0.022 \\
\hline S7 & $\begin{array}{l}\text { Ensure clarity of vision and } \\
\text { strategy of the entity, at all } \\
\text { levels }\end{array}$ & 4.010 & 12.001 & 0.000 & 0.308 & 0.855 & 0.026 & 0.036 & 0.173 \\
\hline S8 & $\begin{array}{l}\text { Keeping the BSC easy to use } \\
\text { with balanced and relevant } \\
\text { number of performance } \\
\text { measures }\end{array}$ & 4.000 & 14.053 & 0.000 & 0.481 & 0.083 & 0.736 & 0.461 & 0.457 \\
\hline S9 & $\begin{array}{l}\text { Ensure all areas of the } \\
\text { organization is measured }\end{array}$ & 3.990 & 12.262 & 0.000 & 0.624 & 0.503 & 0.487 & 0.276 & 0.226 \\
\hline S10 & $\begin{array}{l}\text { Integrated to the management } \\
\text { system / Management } \\
\text { Information Systems of the } \\
\text { organization }\end{array}$ & 3.810 & 11.385 & 0.000 & 0.826 & 0.000 & 0.950 & 0.448 & 0.677 \\
\hline
\end{tabular}

Note: Gend - Gender; Exp. - Experience; C'xity - Complexity

(Source: Survey data)

Ranking of mean values of perceived strategies reveal that the mean values are between 3.81 and 4.33 (see Table 3). It indicates that all strategies have a mean value which is above the average mean value of 3 . Therefore, it is apparent that managers agree on an above average rate that these strategies can be used to count the challenges faced in BSC implementation process. Strategy S1 is ranked highest with a mean value of 4.33. This result indicates that managers of these organizations are more concerned about allocation of appropriate resources to successfully implement the BSC. This finding is consistent with the findings of Dimitropoulos et al. (2017) where they say that 'the human resources are the most significant determinant in the application of a performance-based management methodology'.

5.4.2 One Sample T-Test results of perceived strategies

Table 3 illustrates the results of one sample t-test conducted for perceived strategies. According to Table 3 , it is apparent that the ' $\mathrm{t}$ ' statistic of all ten strategies have positive values ranging from 11.385 to 20.068 . Under the null hypothesis we would expect the ' $t$ ' statistic to be zero, where the mean is equal to 3 . According to this result it can be seen that ' $t$ ' values lie more to the right tail of the distribution. In order to determine whether to reject the null hypothesis for each variable, it must be checked whether it lies far enough in the distribution. This could be determined from the ' $p$ ' value or significance value for all variables. Since all ' $p$ ' values are significant at $95 \%(\mathrm{p}<0.05)$ confidence level, implying that the population means are statistically and significantly different. 
Consequently, we may reject the null hypothesizes, in favour of the alternative hypothesizes. This suggests that FAO organizations consider all the strategies identified in Table 3 as important strategies in the process of BSC design and implementation. These results are consistent with the findings of Assiri et al. (2006), where they identified that providing principles and techniques are required for a successful implementation of BSC and generation of maximum benefit from the BSC.

\subsubsection{One Way Anova Test results of perceived strategies}

5.4.3.1 One-way Anova test between perceived strategies and gender

The first one-way ANOVA test was conducted between perceived strategies and gender. This analysis was performed to see whether the mean values of perceived strategies are significantly different between males and females. The results of the analysis are shown in Table 3. It is apparent that all the resultant ' $p$ ' values are above 0.05. It indicates that none of the differences is significant at the $95 \%$ confidence level. Therefore, we can conclude that there is no statistically significant difference between the responses provided by the male and female respondents in relation to the perceived strategies used for BSC implementation in FAO sector of Sri Lanka.

5.4.3.2 One-way Anova test between perceived strategies and job level

The next one-way ANOVA test was between perceived strategies and job levels of respondents. This test was done to identify whether the mean values of perceived strategies are significantly different between different job levels. The results of the analysis are shown in Table 3. According to the results, it is apparent that challenges S1, S3, S4, S5, S7, S8 and S9, have 'p' values which are above 0.05 indicating that they are not significant at $95 \%$ confidence level. Therefore, we can conclude that for those seven perceived strategies, there is no statistically significant difference between the responses provided by respondents working at different levels in the organization.

However, Table 3 further indicates that other three strategies (S2, S6, and S10) have 'p' values less than 0.05, indicating that they are significant at 95\% confidence level. Therefore, it is apparent for those strategies, there is a significant difference between the responses provided by respondents working in different job levels. This difference was further analysed using 'Post Hoc Test' of SPSS. The results indicated that majority of the time the operations, supervisory and middle management level employees disagreed with the top management in terms of those three strategies.

\subsubsection{One-way Anova test between perceived strategies and total experience}

One-way ANOVA test between perceived strategies and total experience was conducted to examine whether the mean values of perceived strategies are significantly different between employees with different levels of experience. The results are presented in Table 3. From the results it is evident that except for the strategy S7, none of the other strategies are significant at $95 \%$ confidence level $(\mathrm{p}>0.05)$. Therefore, we can conclude that other than for S7, there is no statistically significant difference of the perceived strategies between employees with different experience levels.

\subsubsection{One-way Anova test between perceived strategies and nature of client base}

The next one-way ANOVA test was between perceived strategies and nature of client base. This test was done to determine whether the mean values of perceived challenges are significantly different between three companies with different client bases. The results of the analysis are given in Table 3. Results reveal that for all perceived strategies, except for S5 and S8, have 'p' values that are above 0.05 indicating that they are not significant at 95\% confidence level. Therefore, we can conclude that, except for the strategies S5 and S8, there is no statistically significant difference of perceived strategies between companies with different client bases.

5.4.3.5 One-way Anova test between perceived strategies and complexity of operations

The final one-way ANOVA test was between perceived strategies and complexity of operations of the organizations. This was performed to find out whether the mean values of perceived strategies are significantly different between operations with different complexity levels. The results are shown in Table 3 . The results show that five of the strategies (S1, S3, S4, S5 and S6) are significant at 95\% confidence level $(\mathrm{p}<0.05)$. However, other five strategies found to be not significant at 95\% confidence level.

Five out of the ten variables tested scored a significance or ' $p$ ' value of more than $5 \%$ resulting in no statistically significant difference in the responses provided by the employees in organizations with differing complexities of operations. However, five out of the ten variables tested show a result containing a statistically significant difference among the responses provided by the respondents in differing operation complexities.

\section{Conclusion}

In terms of the benefits of the BSC, this study reveals that managers of the FAO industry are more concerned with the ability of the tool to offer measurement in aspects other than the financial aspects. This finding is in line with Northcott et al. (2012), that states "action directed at improving outcomes on the "leading" indicators (in the first three dimensions) will ultimately drive performance improvement in the fourth, "lagging" dimension (i.e. financial outcomes)". All employees agree on the ability of the tool in providing very important benefits, while 
the responses provided do not differ based on the gender and complexity of operations, difference in client base nor the experience in the sector.

Further, the study reveals that employees in this industry consider the lack of proper education and training on the tool to be one of the main challenges. This response had a unanimous agreement between the two genders. This was stressed by Dimitropoulos et al. (2017) in his research urging employees to seek additional education and training in any form. All employees agreed on all other challenges tested, however the responses varied between the differing control variables.

Finally, in terms of the strategies to overcome the identified challenges, it is important to ensure that appropriate resources are made available in order to have successful implementation of the BSC. This again was unanimously agreed by both genders. Johanson et al., (2006) identified the same as an important strategy in his study conducted on the dilemmas of this performance measurement tool. On analysis of all other strategies tested, the responses varied between the control variables.

The author acknowledges several limitations in the study. Firstly, the study was entirely based on responses received through a questionnaire method. This was due to the requirement of the companies under study to maintain confidentiality. However further interviews and discussions would have enabled the researcher to understand and identify more in-depth details in terms of the objectives under study. Secondly, the findings presented in this study can only be generalized to the Finance and Accounting Outsourcing sector of Sri Lanka. In order to attain a more applicable generalization, this analysis should be applied to other industrial sectors as well as other countries. Thirdly, the study undertook a cross sectional study. A longitudinal study could have provided more accuracy to the data obtained. Finally, the study focuses on only three variables namely benefits, challenges and strategies. However, there could be other variables which could influence the successful implementation of BSC.

\section{References}

accenture, 2017. Available at: https://www.accenture.com/us-en/company [Accessed 01.12.2017].

Assiri, A., Zairi, M. \& Eid, R., 2006. How to profit from the balanced scorecard: An implementation roadmap. Industrial Management \& Data Systems, 106(7), pp. 937-952.

Bean, L. and Jarnagin, B.D. (2002), "New cost priorities: using a balanced scorecard in financial reports",The Journal of Corporate Accounting and Finance, Vol. 13 No. 3, pp. 55-62.

Dimitropoulos, P., Kosmas, I. \& Douvis, I., 2017. Implementing the balanced scorecard in a local government sport organization:Evidence from Greece. International Journal of Productivity and Performance Management, 66(3), pp. 362-379.

Evans, N., 2005. Assessing the balanced scorecard as a management tool for hotels. International Journal of Contemporary Hospitality Management, 17(5), pp. 376 - 390.

Geller, A., 1985. Tracking the critical success factors for. The Cornell HRA Quarterly, pp. 76-81.

Habte, D. (2015). Prospects and Challenges of Balanced Implementation: A Case of Development Bank of Ethiopia.

Ho, S.-J. K. \& McKay, R. B., 2002. Balanced Scorecard: Two Perspectives. The CPA Journal.

Johanson, U., Skoog, M., Backlund, A. \& Almqvist, R., 2006. Balancing dilemmas of the balanced scorecard. Accounting, Auditing \& Accountability Journal, 19(6), pp. 842-857.

Kaplan, R. S., \& Norton, D. P. (1996). Using the Balanced Scorecard as a Strategic Management System. Harvard Business Review.

Kaplan, R.S. \& Norton, D.P. (2005), "The balanced scorecard: measures that drive performance", Harvard Business Review, Vol. 83, pp. 172-80.

Letza, S. R., 1996. The design and implementation of the balanced business scorecard: An analysis of three companies in practice. Business Process Re-engineering \& Management Journal, 2(3), pp. 54-76.

McDonnell, J. B. B. B., 1995. The balanced score-card: short-term guest or long-term resident?. International Journal of Contemporary Hospitality Management, 7(2/3), pp. 7 - 11.

Northcott, D. \& Ma'amora Taulapapa, D. N. T., 2012. Using the balanced scorecard to manage performance in public sector organizations:Issues and challenges. International Journal of Public Sector Management, 25(3), pp. 166-191.

Olsson, B., Karlsson, M. \& Sharma, E., 2000. Towards a Theory of Implementing the Balance Scorecard: A Study in Association with the Swedish Telecommunication Firm Ericsson. Journal of Human Resource Costing \& Accounting, 5(1), pp. 59-84.

Paranjape, B., Rossiter, M. \& Pantano, V., 2006. Performance measurement systems: successes, failures and future - a review. Measuring Business Excellence, 10(3), pp. 4-14.

Ratnasingam, P., 2009. Service quality management applying the balanced scorecard : an exploratory study. International Journal of Commerce and Management, 19(2), pp. 127-136.

Roest, P., 1997. The golden rules for implementing the balanced business scorecard. Information Management \& 
Computer Security, 5(5), pp. 163-165.

Sanger, M., 1998. Supporting the balanced scorecard. Work Study, 47(6), pp. 197-200.

Soderberg, M., Kalagnanam, S., Sheehan, N. T. \& Vaidyanathan, G., 2011. When is a balanced scorecard a balanced scorecard?. International Journal of Productivity and Performance Management, 60(7), pp. 688708.

Wickramasinghe, D., Gooneratne, T. \& Jayakody, J., 2008. Interest lost: The Rise And Fall Of A Balanced Scorecard Project In Sri Lanka. Advances in Public Interest Accounting, Volume 13, p. 237-271. 